\title{
Treatment of pulmonary hypertension in patients with connective tissue disease and interstitial lung disease
}

\author{
Shikha Mittoo MD MHS FRCPC ${ }^{1,2}$, Thomas Jacob MD FRCPC ${ }^{1}$, Andrea Craig BSc ${ }^{1}$, Zoheir Bshouty MD PhD FRCPC ${ }^{1}$
}

S Mittoo, T Jacob, A Craig, Z Bshouty. Treatment of pulmonary hypertension in patients with connective tissue disease and interstitial lung disease. Can Respir J 2010;17(6):282-286.

BACKGROUND: Pulmonary hypertension $(\mathrm{PH})$ in patients with connective tissue disease (CTD) can occur in isolation or concomitantly with interstitial lung disease (ILD). Targeted therapies for $\mathrm{PH}$ can mitigate clinical deterioration in CTD patients with isolated $\mathrm{PH}$; however, the effect of these therapies in CTD patients with PH and ILD (CTD-PH-ILD) are poorly characterized.

OBJECTIVE: To investigate outcomes following long-term treatment of $\mathrm{PH}$ in patients with CTD-PH-ILD.

METHODS: A retrospective evaluation of 13 CTD-PH-ILD patients who were treated with bosentan, sildenafil or bosentan plus sildenafil, was conducted. Immunosuppressants were prescribed as indicated. Patients underwent pulmonary function testing and assessment of 6 min walk distance at the time of treatment initiation and during follow-up. Patients were followed until time of death, lung transplantation or the end of the study. Kaplan-Meier estimates of survival were calculated and log-rank testing was used to analyze survival differences according to CTD subtype.

RESULTS: Thirteen patients (seven with systemic sclerosis [SSc], four with overlap syndrome, and two with rheumatoid arthritis) were followed for a mean $( \pm S D)$ duration of $33.8 \pm 21.7$ months. The survival estimate at a median duration of 34 months was $85 \%$; two patients with SSc died. Mortality rates were greater among patients with SSc versus other CTD subtypes $(\mathrm{P}=0.04)$. No changes from baseline to follow-up in mean forced vital capacity or exercise capacity, and no treatment-related toxicity, were observed.

CONCLUSION: Treatment using PH-specific therapies in patients with CTD, PH and ILD was well tolerated. Further studies to investigate the efficacy of $\mathrm{PH}$-specific therapies in CTD-PH-ILD patients are warranted.

Key Words: Exercise capacity; Overlap syndrome; Pulmonary function; Rheumatoid arthritis; Survival; Systemic sclerosis

\author{
Le traitement de l'hypertension pulmonaire chez \\ des patients ayant une maladie des tissus \\ conjonctifs et une maladie pulmonaire interstitielle
}

\begin{abstract}
HISTORIQUE : L'hypertension pulmonaire (HP) chez les patients ayant une maladie des tissus conjonctifs (MTC) peut se manifester isolément ou conjointement avec une maladie pulmonaire interstitielle (MPI). Des thérapies ciblées de l'HP peuvent limiter la détérioration clinique de la MTC chez les patients ayant une HP isolée, mais l'effet de ces thérapies sur les patients ayant une MTC accompagnée d'une HP et d'une MPI (MTCHP-MPI) est mal caractérisé.

OBJECTIF : Examiner les issues après un traitement à long terme de l'HP chez les patients ayant une MTC-HP-MPI.

MÉTHODOLOGIE : Les chercheurs ont procédé à une évaluation rétrospective de 13 patients ayant une MTC-HP-MPI traités au bosentan, au sildénafil ou au bosentan et au sildénafil. Des immunosuppresseurs leur étaient prescrits selon les indications. Les patients ont subi une exploration fonctionnelle respiratoire et une évaluation de la distance de marche en 6 minutes au début du traitement, puis pendant le suivi. Ils ont été suivis jusqu'à leur décès, à une transplantation pulmonaire ou à la fin de l'étude. Les chercheurs ont calculé les évaluations de survie de KaplanMeier et ont utilisé le test de Mantel-Haenzel pour analyser les différences de survie selon le sous-type de MTC.

RÉSULTATS : Treize patients (sept ayant une sclérose systémique [ScS], quatre, un syndrome de chevauchement et deux, une polyarthrite rhumatoïde) ont été suivis pendant une période moyenne $( \pm E$ ET $)$ de 33,8 $\pm 21,7$ mois. L'évaluation de survie après une période médiane de 34 mois était de $85 \%$; deux patients atteints de ScS étaient décédés. Le taux de mortalité était plus élevé chez les patients atteints d'une ScS que chez ceux ayant d'autres soustypes de MTC $(\mathrm{P}=0,04)$. Les chercheurs n'ont observé ni changement entre le point de départ et le suivi pour ce qui est de la capacité vitale forcée moyenne ou de la capacité à l'effort, ni toxicité liée au traitement.

CONCLUSION : Un traitement faisant appel à des thérapies propres à l'HP chez les patients ayant une MTC, une HP et une MPI était bien toléré. D'autres études pour examiner l'efficacité des thérapies propres à l'HP chez des patients atteints de MTC-HP-MPI s'imposent.
\end{abstract}

$\mathrm{T}$ he term 'connective tissue disease' (CTD) is applied to a heterogeneous group of disorders including systemic sclerosis (SSc), systemic lupus erythematosus (SLE), idiopathic inflammatory myositis (IIM), rheumatoid arthritis (RA), primary Sjögren's syndrome and mixed connective tissue disease (MCTD). A well-known complication of CTD is pulmonary hypertension $(\mathrm{PH})$, which may develop in isolation or in association with interstitial lung disease (ILD) (1-3). CTDassociated PH (CTD-PH) is a leading cause of mortality; patients with this manifestation have an estimated three-year survival rate of $56 \%(4,5)$. Less is known about survival among patients with CTD, PH and ILD (CTD-PH-ILD), although reported observations suggest that the prognosis for these patients is particularly poor $(2,6)$. In a recent study by Mathai et al (7), patients with SSc, PH and ILD had an estimated three-year survival rate of $39 \%$, a rate five-times worse than the rate observed in patients with SSc or $\mathrm{PH}$ alone (7).
Clinical trial data (8-13) show that $\mathrm{PH}$-specific therapies (prostanoids, endothelin receptor antagonists and phosphodiesterase type 5 inhibitors) improve hemodynamic parameters, exercise capacity, health-related quality of life and, possibly, survival in CTD-PH patients. However, patients with CTD-PH and significant ILD were typically excluded from these trials due to concerns regarding worsening ventilation/perfusion mismatch and shunt, and the impact of these physiological changes on outcomes such as exercise capacity and survival (14). As a result, little is known about the impact of $\mathrm{PH}$-specific therapies on survival and exercise capacity in CTD-PH-ILD patients.

The present article reports the results of a retrospective analysis of outcomes in CTD-PH-ILD patients who were treated with long-term, $\mathrm{PH}$-specific therapies at a tertiary referral centre. Using Kaplan-Meier estimates, the outcomes investigated included survival and baseline changes in exercise capacity and pulmonary function.

\footnotetext{
${ }^{1}$ Department of Medicine, University of Manitoba, Winnipeg, Manitoba; ${ }^{2}$ Department of Medicine, University of Toronto, Toronto, Ontario

Correspondence: Dr Shikha Mittoo, 60 Murray Street, L2-005, Toronto, Ontario M5T 3L9. Telephone 416-586-8447, fax 416-586-8766,

e-mailsmittoo@mtsinai.on.ca
} 


\section{METHODS}

\section{Study design and patient population}

The present study was a retrospective analysis of data from the University of Manitoba Pulmonary Hypertension clinic registry (Winnipeg, Manitoba). Patients with CTD-PH-ILD in the absence of other secondary etiologies, who received bosentan between July 1, 2001, and November 3, 2008, were included in the analysis.

Patients exhibiting SSc, SLE, IIM, RA, primary Sjögren's syndrome and MCTD, diagnosed by a rheumatologist were included in the analysis. The presence of overlap syndrome was recorded among patients diagnosed with more than one CTD, which included patients with MCTD.

$\mathrm{PH}$ was defined as a resting mean pulmonary arterial pressure of $25 \mathrm{mmHg}$ or greater, a pulmonary vascular resistance (PVR) of more than 3.0 Wood units $/ \mathrm{m}^{2}$ and a pulmonary capillary wedge pressure of lower than $15 \mathrm{mmHg}$ on right heart catheterization (RHC). In cases for which a patient refused or could not tolerate RHC, an estimated right ventricular systolic pressure of $45 \mathrm{mmHg}$ or greater, as measured by Doppler echocardiography in the absence of left heart failure, was used to define $\mathrm{PH}$.

The presence of ILD was defined as a forced vital capacity (FVC) of lower than $80 \%$ of predicted. The severity of ILD was categorized as mild in patients with an FVC of $70 \%$ to $80 \%$ of predicted values, and moderate to severe in patients with an FVC of $70 \%$ of predicted values or lower (15).

\section{Data collection and assessments}

The primary end points for patients in the present study were death or lung transplantation. The follow-up period (survival) in patients who met either primary end point comprised the duration from the initiation of $\mathrm{PH}$-specific therapy until the date of the event. For patients who did not meet either end point, the follow-up period (survival) comprised the duration from date of initiation of $\mathrm{PH}$-specific therapy until the date of the most recent clinic visit.

All patients required a pulmonary function test (PFT) and 6 min walk distance (6MWD) results to be measured within six months of $\mathrm{PH}$-specific treatment initiation (baseline) and at time of follow-up to be included in the present study.

PFTs included spirometry, measurements of lung volume and single-breath carbon monoxide diffusing capacity (DLCO); measurements were standardized to reference data reported by Gutierrez et al (16). The PFT results measured closest to bosentan initiation (baseline) and the most recently available PFT results (follow-up) were used for analysis. Progressive decline in lung function was defined as a decrease in FVC of $10 \%$ of predicted or greater from baseline to follow-up assessment.

Measurement of 6WMD was performed using a standardized protocol among patients breathing room air. The total distance walked (in $\mathrm{m}$ ), oxygen saturation, fraction of inspired oxygen, and reason(s) for early termination (when applicable) were recorded. Reference equations from Enright and Sherrill (17) were used for assessment. The assessment of 6MWD was performed approximately every four to six months in patients treated with $\mathrm{PH}$-specific therapies; the assessment of 6MWD conducted closest to bosentan initiation (baseline) and the most recently available assessment of 6MWD (follow-up) were used in the analyses.
Other clinical variables quantified at baseline included demographics, concomitant medications and WHO functional class. Hemodynamic parameters obtained during RHC included mean pulmonary arterial pressure, pulmonary capillary wedge pressure, calculated PVR and cardiac index. Alanine and aspartate aminotransferase levels were monitored weekly for the first eight weeks of bosentan therapy, and monthly thereafter.

\section{Statistical analysis}

Analyses were performed using Stata Statistical Software release 9 (StataCorp, USA). The duration of follow-up, and results of cardiac hemodynamics, FVC (\% predicted), DLCO (\% predicted) and 6MWD $(\mathrm{m})$ are expressed as mean \pm SD. Paired $t$ tests were used to determine differences in FVC or 6MWD at baseline and at follow-up. Kaplan-Meier analysis was used for investigation of survival. A log-rank test was used to analyze survival differences according to CTD subtype.

\section{Study population}

\section{RESULTS}

In total, 13 CTD-PH-ILD patients who were treated with bosentan were identified and included in the study. Baseline characteristics and demographics are presented in Table 1. Six patients exhibited mild ILD and seven had moderate to severe ILD. Twelve patients were Caucasian and one was a First Nations person. The mean DLCO at baseline for the study group was $37.2 \pm 9.8 \%$ of predicted values.

Hemodynamic measurements from 12 patients who underwent RHC for diagnosis of PH are presented in Table 2. One patient was diagnosed with $\mathrm{PH}$ using Doppler echocardiography. This patient exhibited an estimated right ventricular systolic pressure of $48 \mathrm{mmHg}$ and an oxygen saturation of $91 \%$ on room air.

\section{Treatment}

All patients received initial monotherapy with bosentan $62.5 \mathrm{mg}$ twice daily for four weeks, up-titrated to $125 \mathrm{mg}$ twice daily thereafter. Patients were followed at least every three months and switched to sildenafil - a phosphodiesterase 5 inhibitor - if their 6MWD fell below $350 \mathrm{~m}$ or their New York Heart Association functional class remained at class III. Four patients eventually required a combination of bosentan plus sildenafil. Sildenafil $25 \mathrm{mg}$ was administered three times daily. $\mathrm{PH}$-specific treatment was well tolerated, and no episodes of treatmentrelated toxicity were observed.

In addition to specific $\mathrm{PH}$-therapies, nine patients (69\%) received a diuretic, five (38\%) were taking warfarin, five (38\%) were on supplemental oxygen, four $(31 \%)$ were taking a calcium channel blocker and two (15\%) were taking digoxin. Concomitant immunosuppressant therapy was ongoing in 10 patients at baseline (Table 1 ).

\section{Survival during follow-up}

Patients were followed for a mean duration of $33.8 \pm 21.7$ months (range three to 75 months). The Kaplan-Meier survival estimates for all patients in the study population are illustrated in Figure 1. Eleven patients (85\%) survived a median of 34 months from bosentan initiation. No patients required a lung transplant.

Two patients (15\%) died from end-stage $\mathrm{PH}$ during the study period - both were on a combination of bosentan and 
TABLE 1

Baseline characteristics of patients included in the study

\begin{tabular}{|c|c|c|c|c|c|c|c|c|c|c|c|c|c|}
\hline $\begin{array}{l}\text { Patient } \\
\text { ID }\end{array}$ & Sex & $\begin{array}{c}\text { Smoking } \\
\text { status*, } \\
\text { pack-years }\end{array}$ & CTD & $\begin{array}{l}\text { Age, } \\
\text { years }\end{array}$ & $\begin{array}{l}\text { WHO } \\
\text { class }\end{array}$ & $\begin{array}{c}\text { FVC, } \% \\
\text { predicted }\end{array}$ & $\begin{array}{c}\text { DLco, } \\
\text { \% predicted }\end{array}$ & $\mathrm{FEV}_{1} / \mathrm{FVC}$ & $\begin{array}{l}\mathrm{mPAP} \\
\mathrm{mmHg}\end{array}$ & $\begin{array}{l}\text { PVR, } \\
\text { Wood } \\
\text { units }\end{array}$ & RAP, $\mathrm{mmHg}$ & 6MWD, m & IT \\
\hline 1 & Female & $\mathrm{N}$ & Ov & 68 & III & 54 & 39 & 88 & 33 & 4.3 & 1 & 260 & P/A \\
\hline 2 & Male & 25 & SSc & 68 & III & 76 & 33 & 74 & 33 & 3.8 & 5 & 360 & - \\
\hline 3 & Female & 3 & Ov & 34 & III & 32 & 21 & 89 & 28 & 5.0 & 7 & 520 & P/CYC \\
\hline $4^{\dagger}$ & Female & $\mathrm{N}$ & $\mathrm{SSc}$ & 67 & II & 77 & 46 & 82 & 55 & 11.2 & - & 363 & A \\
\hline 5 & Female & 36 & SSc & 59 & IV & 72 & 38 & 69 & 63 & 12.1 & - & 360 & - \\
\hline 6 & Male & 30 & RA & 56 & IV & 64 & 40 & 64 & 55 & 14.0 & 8 & 190 & $\mathrm{~T}$ \\
\hline $7^{\dagger}$ & Female & 2 & $\mathrm{SSc}$ & 75 & III & 73 & 44 & 82 & 52 & 15.3 & 4 & 335 & $P$ \\
\hline 8 & Male & $\mathrm{N}$ & SSc & 58 & II & 74 & 28 & 79 & 28 & 4.1 & 4 & 416 & - \\
\hline 9 & Female & $\mathrm{N}$ & $\mathrm{SSc}$ & 66 & III & 35 & 22 & 66 & 39 & 5.0 & 6 & 295 & $\mathrm{P}$ \\
\hline 10 & Female & $\mathrm{N}$ & $\mathrm{RA}$ & 48 & II & 61 & 56 & 85 & 45 & 6.8 & 4 & 505 & $\mathrm{P} / \mathrm{T} / \mathrm{L}$ \\
\hline 11 & Male & 68 & Ov & 47 & II & 56 & 33 & 78 & - & - & - & 300 & $\mathrm{P} / \mathrm{H}$ \\
\hline 12 & Female & 15 & $\mathrm{SSc}$ & 64 & II & 72 & 43 & 68 & 29 & 6.8 & 18 & 510 & MTX \\
\hline 13 & Female & $\mathrm{N}$ & Ov & 26 & IV & 40 & 40 & 97 & 30 & 5.4 & 1 & 280 & $\mathrm{P} / \mathrm{A} / \mathrm{H}$ \\
\hline Mean & - & - & - & 56.6 & 2.9 & 60.5 & 37.2 & 78.5 & 40.8 & 7.8 & 5.8 & 361.1 & - \\
\hline SD & - & - & - & 14.3 & 0.8 & 16.0 & 9.8 & 10.0 & 12.6 & 4.2 & 4.8 & 102.5 & - \\
\hline
\end{tabular}

${ }^{*}$ All patients were nonsmokers at the time of assessment; ${ }^{\dagger}$ Patient died. 6MWD 6 min walk distance; A Azathioprine; CTD Connective tissue disease; CYC Cyclophosphamide; DLco Carbon monoxide diffusing capacity; FEV 1 Forced expiratory volume in 1 s; FVC Forced vital capacity; H Hydroxychloroquine; IT Immunotherapy; L Leflunomide; mPAP Mean pulmonary arterial pressure; MTX Methotrexate; N Never smoker; Ov Overlap; P Prednisone; PVR Pulmonary vascular resistance; RA Rheumatoid arthritis; RAP Right atrial pressure; SSc Systemic sclerosis; T Tumour necrosis factor-alpha inhibitor

TABLE 2

Baseline hemodynamic parameters in patients who underwent right heart catheterization

\begin{tabular}{lc}
\hline Parameter & Mean \pm SD \\
\hline Pulmonary arterial pressure, $\mathrm{mmHg}$ & $40.8 \pm 12.6$ \\
Pulmonary capillary wedge pressure, $\mathrm{mmHg}$ & $10.0 \pm 3.6$ \\
Cardiac index, L/min $/ \mathrm{m}^{2}$ & $2.5 \pm 0.9$ \\
Pulmonary vascular resistance, Wood units $/ \mathrm{m}^{2}$ & $7.8 \pm 4.2$ \\
\hline
\end{tabular}

sildenafil at time of death. The first death occurred 27 months following $\mathrm{PH}$-specific treatment initiation. In this patient, the most recently available measurements of FVC and 6MWD were $65 \%$ of predicted values and $85 \mathrm{~m}$, respectively. The second death occurred 17 months following initiation of $\mathrm{PH}$-specific therapy, with the most recent available measurements of FVC and 6MWD being 67\% of predicted values and $310 \mathrm{~m}$, respectively. Intravenous epoprostenol therapy was considered to be an appropriate alternative treatment for these patients; however, ultimately, it was not prescribed because both patients exhibited an inability to self-administer.

All survivors exhibited a CTD other than SSc (four patients had overlap syndrome and two patients had RA); both patients who died had SSc. Using log-rank testing, a significantly greater mortality rate was observed among patients with SSc $(n=7)$ compared with other CTD $(n=6)(P=0.04)$.

\section{Change in FVC}

The first assessment of PFT results was performed at a mean of 3.3 months (range zero to 23 months) from bosentan initiation. The final assessment of PFT results was at a mean duration of 32.1 months (range 11 to 76 months) following the first assessment. With the exception of two patients who died, the final assessment of PFT results occurred on the same date as the most recently recorded follow-up visit. Of the two patients who died, the most recently available assessments of PFT results were conducted five days before death in one patient and five months before death in the other.

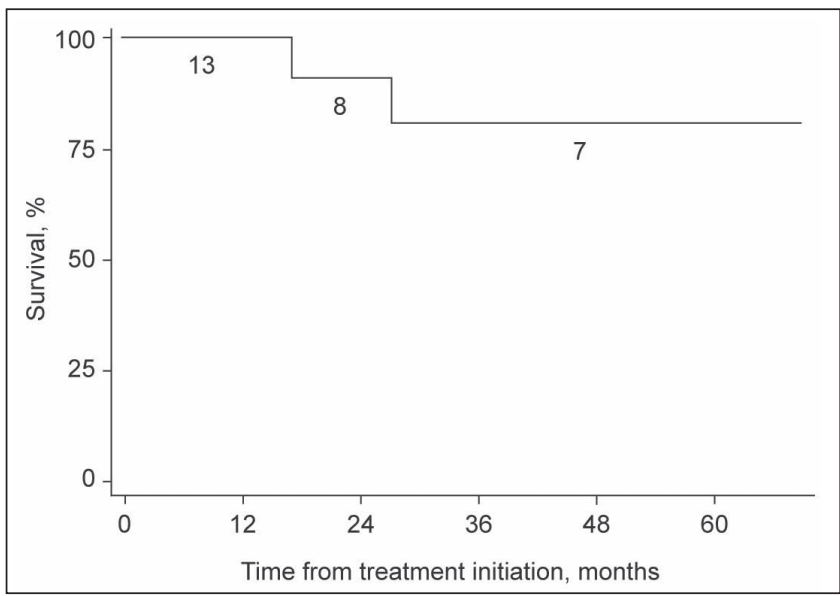

Figure 1) Kaplan-Meier survival estimates for patients with connective tissue disease, pulmonary hypertension and interstitial lung disease who were treated with pulmonary hypertension-specific therapies

The mean and per-patient measurements of FVC at baseline and at the time of follow-up assessment are reported in Figure 2. The mean FVC at baseline was $60.5 \pm 16.0 \%$ of predicted values and the mean FVC at follow-up was $62.1 \pm 13.9 \%$ of predicted values. While no significant differences were observed between the two means, three patients exhibited a decline in lung function (defined by a decrease in FVC of $10 \%$ of predicted or greater) between their baseline and follow-up assessments.

\section{Change in 6MWD}

The first assessment of 6MWD was performed at a mean of 2.3 months (range zero to 23 months) from bosentan initiation. The final assessment of 6MWD was conducted at a mean duration of 36.1 months (range seven to 70 months) following the first assessment. The 6MWD was assessed in all patients within a mean period of one month (range zero to four months) from their most recent follow-up date. 


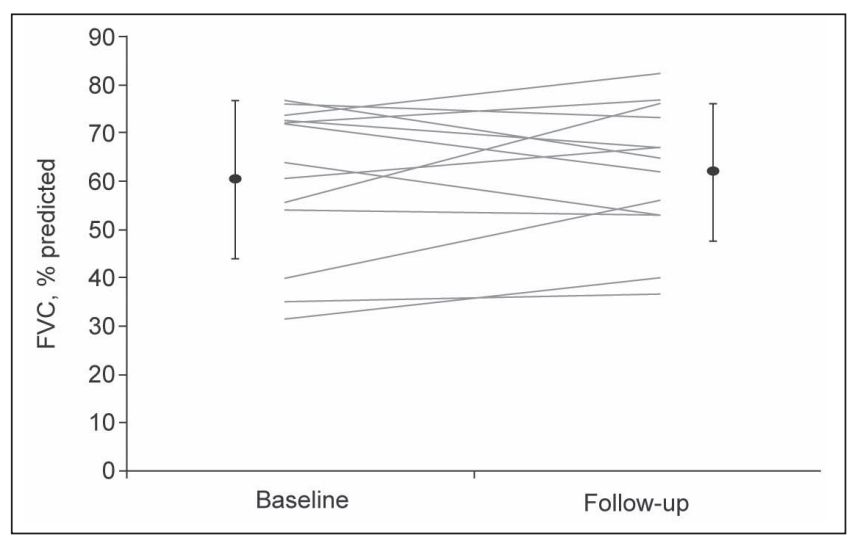

Figure 2) Mean and per-patient forced vital capacity (FVC) at baseline and at follow-up. Data presented as mean \pm SD

The mean and per-patient measurements of 6MWD at baseline and at time of follow-up assessment are illustrated in Figure 3. At baseline, the mean 6MWD was $361.1 \pm 102.5 \mathrm{~m}$. At follow-up, the mean 6MWD was $353.0 \pm 127.0 \mathrm{~m}$. One patient exhibited a notable decline in 6MWD between baseline and follow-up assessment.

\section{DISCUSSION}

$\mathrm{PH}$ and ILD are prevalent, and lead the causes of mortality in CTD patients (5). In CTD, PH may develop either as a consequence of progressive ILD or as a complication of the disease. In the present study, we observed a median 34-month KaplanMeier survival estimate of $85 \%$ among CTD-PH-ILD patients treated with $\mathrm{PH}$-specific medications. A significantly greater mortality was observed among patients with SSc compared with other CTDs. No significant changes in mean FVC or 6MWD were observed during the treatment period - a maintenance of clinical status that may be considered to be a success. $\mathrm{PH}$-specific treatment was well tolerated in this population.

Little is known about the survival of CTD-PH-ILD patients on $\mathrm{PH}$-specific therapies. In one single-centre study from the United States, Mathai et al (7) observed a three-year survival rate of $39 \%$ among patients with SSc, $\mathrm{PH}$ and ILD who received $\mathrm{PH}$-specific treatment. In this study, 15 of $20 \mathrm{SSc}$ patients with $\mathrm{PH}$ and ILD received an endothelin receptor antagonist, but still experienced a poor outcome. In a multicentre observational study from the United Kingdom (18), patients diagnosed with CTD-PH and significant ILD exhibited a three-year survival rate of only $28 \%$ despite $\mathrm{PH}$ treatment. Furthermore, SSc patients may fare worse than patients with another CTD $(2,18)$. The survival rate we report was higher than in previous reports and may be explained by the fact that several patients in this population exhibited a CTD other than SSc. Condliffe et al (18) reported three-year survival estimates among patients with $\mathrm{PH}$ associated with SLE, MCTD, RA and IIM of 74\%, 63\%, 66\% and 100\%, respectively. The authors also observed that patients with SLE and IIM exhibited significantly better survival than patients with SSc undergoing $\mathrm{PH}$ treatment (18). In another study of 12 SLE-PH patients treated with $\mathrm{PH}$-specific medications (19), there were no deaths or need for lung transplantation observed at a mean follow-up period of 41 months.

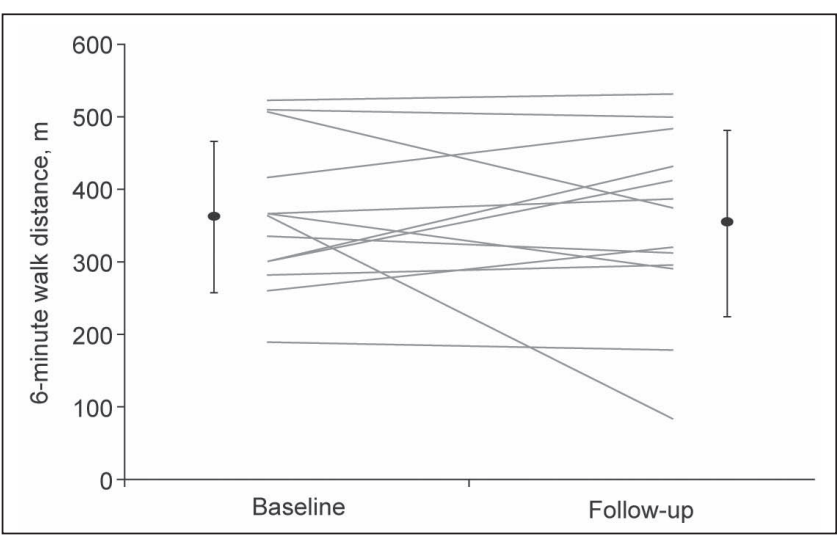

Figure 3) Mean and per-patient 6 min walk distance at baseline and at follow-up. Data presented as mean \pm SD

The clinical characteristics and demographics of our patient population also differ from previous reports. With the exception of one First Nations patient, our study group was comprised of Caucasian patients only. Mathai et al also showed that a low per cent predicted DLCO and high PVR index were significantly associated with mortality in SSc patients with $\mathrm{PH}$ and ILD (7). In contrast, our study population exhibited a greater mean $\mathrm{DL}_{\mathrm{CO}}$ and a lower PVR than the SSc patients with PH and ILD studied by Mathai et al (7).

Notably, our study group was not treated with an endothelinreceptor antagonist as monotherapy. In accordance with the treatment regimen, patients could receive sildenafil or epoprostenol monotherapy; four patients received combination bosentan and sildenafil therapy. Using combinations of $\mathrm{PH}$-specific therapies may improve survival in CTD-PH patients. Condliffe et al (18) observed that two-year survival (71\%) was greater among SSc-PH patients treated with combination therapy versus patients on endothelin receptor antagonist monotherapy $(51 \%)$. Furthermore, 10 patients $(77 \%)$ in our study population received concomitant immunosuppression for ILD. PH in patients with some CTD may respond well or even reverse following immunosuppressive medications (20-24). However, mean pulmonary arterial pressure in SSc patients with PH and ILD does not typically improve with immunosuppressive treatment, suggesting that $\mathrm{PH}$, at least in SSc, should be treated with $\mathrm{PH}$-specific therapies. This is particularly important given that $\mathrm{PH}$ is independently associated with mortality in SSc-PH patients with ILD (25). An additional benefit to patients in our study population may have resulted from the use of anticoagulation therapy in the non-SSc patients with $\mathrm{PH}(7,26)$.

We acknowledge several limitations in the present observational, retrospective study. While data collection was detailed, the patient population was small and the study was not powered to detect differences in survival according to clinical features. In addition, our patient population represented a selected group who were referred for $\mathrm{PH}$ evaluation at a tertiary care hospital in Canada, and may not be representative of the broader CTD-PH-ILD patient population. We cannot ascribe the observed survival rate merely to treatment with $\mathrm{PH}$-specific therapies; this survival rate may reflect lead time bias or concomitant treatment with immunosuppressants. 


\section{CONCLUSION}

A Kaplan-Meier survival estimate of $85 \%$ at 34 months was observed among CTD-PH-ILD patients who were treated with $\mathrm{PH}$-specific therapies and immunosuppressants. The treatment regimens were well tolerated. Controlled trials to investigate the efficacy of $\mathrm{PH}$-specific therapies in this CTD patient population are warranted.

ACKNOWLEDGEMENTS: Editorial assistance was provided by Elements Communications Ltd (Westerham, United Kingdom) and funded by Actelion Pharmaceuticals Ltd (Allschwil, Switzerland).

CONFLICTS OF INTEREST: Shikha Mittoo has received honoraria for consultancy work with Actelion Pharmaceuticals Ltd (Allschwil, Switzerland). Zoheir Bshouty has received research funding from Actelion Pharmaceuticals Ltd. Thomas Jacob and Andrea Craig have no conflicts of interest to declare.

\section{REFERENCES}

1. Mukerjee D, St George D, Coleiro B, et al. Prevalence and outcome in systemic sclerosis associated pulmonary arterial hypertension: Application of a registry approach. Ann Rheum Dis 2003;62:1088-93.

2. Wigley FM, Lima JA, Mayes M, McLain D, Chapin JL, Ward-Able C. The prevalence of undiagnosed pulmonary arterial hypertension in subjects with connective tissue disease at the secondary health care level of community-based rheumatologists (the UNCOVER study). Arthritis Rheum 2005;52:2125-32.

3. Owens GR, Fino GJ, Herbert DL, et al. Pulmonary function in progressive systemic sclerosis. Comparison of CREST syndrome variant with diffuse scleroderma. Chest 1983;84:546-50.

4. Steen VD, Conte C, Owens GR, Medsger TA Jr. Severe restrictive lung disease in systemic sclerosis. Arthritis Rheum 1994;37:1283-9.

5. Steen VD, Medsger TA. Changes in causes of death in systemic sclerosis, 1972-2002. Ann Rheum Dis 2007;66:940-4.

6. Condliffe R, Kiely DG, Peacock AJ, et al. Connective tissue disease associated pulmonary arterial hypertension in the modern treatment era. Am J Respir Crit Care Med 2009;179:151-7.

7. Mathai SC, Hummers LK, Champion HC, et al. Survival in pulmonary hypertension associated with the scleroderma spectrum of diseases: Impact of interstitial lung disease. Arthritis Rheum 2009;60:569-77.

8. Budde-Steffen C, Gravinghoff L, Albani M, Hellwege HH, Kohlschutter A. [Nightly home artificial respiration in juvenile Pompe's disease with pulmonary hypertension and right cardiac insufficiency.] Dtsch Med Wochenschr 1989;114:1114-6.

9. Badesch DB, Tapson VF, McGoon MD, et al. Continuous intravenous epoprostenol for pulmonary hypertension due to the scleroderma spectrum of disease. A randomized, controlled trial. Ann Intern Med 2000;132:425-34.

10. Rubin LJ, Badesch DB, Barst RJ, et al. Bosentan therapy for pulmonary arterial hypertension. N Engl J Med 2002;346:896-903.
11. Denton CP, Pope JE, Peter HH, et al. Long-term effects of bosentan on quality of life, survival, safety and tolerability in pulmonary arterial hypertension related to connective tissue diseases. Ann Rheum Dis 2008;67:1222-8.

12. Denton CP, Humbert M, Rubin L, Black CM. Bosentan treatment for pulmonary arterial hypertension related to connective tissue disease: A subgroup analysis of the pivotal clinical trials and their open-label extensions. Ann Rheum Dis 2006;65:1336-40.

13. Girgis RE, Frost AE, Hill NS, et al. Selective endothelin A receptor antagonism with sitaxsentan for pulmonary arterial hypertension associated with connective tissue disease. Ann Rheum Dis 2007;66:1467-72.

14. Olschewski H, Ghofrani HA, Walmrath D, et al. Inhaled prostacyclin and iloprost in severe pulmonary hypertension secondary to lung fibrosis. Am J Respir Crit Care Med 1999; 160:600-7.

15. American Thoracic Society. Lung function testing: Selection of reference values and interpretative strategies. Am Rev Respir Dis 1991;144:1202-18.

16. Gutierrez C, Ghezzo RH, Abboud RT, et al. Reference values of pulmonary function tests for Canadian Caucasians. Can Respir J 2004;11:414-24.

17. Enright PL, Sherrill DL. Reference equations for the six-minute walk in healthy adults. Am J Respir Crit Care Med 1998;158:1384-7.

18. Condliffe R, Kiely DG, Peacock AJ, et al. Connective tissue disease-associated pulmonary arterial hypertension in the modern treatment era. Am J Respir Crit Care Med 2009;179:151-7.

19. Heresi GA, Minai OA. Lupus-associated pulmonary hypertension: Long-term response to vasoactive therapy. Respir Med 2007;101:2099-107.

20. Groen H, Bootsma H, Postma DS, Kallenberg CG. Primary pulmonary hypertension in a patient with systemic lupus erythematosus: Partial improvement with cyclophosphamide. J Rheumatol 1993;20:1055-7.

21. Jais X, Launay D, Yaici A, et al. Immunosuppressive therapy in lupus- and mixed connective tissue disease-associated pulmonary arterial hypertension: A retrospective analysis of twenty-three cases. Arthritis Rheum 2008;58:521-31.

22. Tam LS, Li EK. Successful treatment with immunosuppression, anticoagulation and vasodilator therapy of pulmonary hypertension in SLE associated with secondary antiphospholipid syndrome. Lupus 1998;7:495-7.

23. Ribeiro JM, Lucas M, Victorino RM. Remission of precapillary pulmonary hypertension in systemic lupus erythematosus. J R Soc Med 2001;94:32-3.

24. Goupille P, Fauchier L, Babuty D, Fauchier JP, Valat JP. Precapillary pulmonary hypertension dramatically improved with high doses of corticosteroids during systemic lupus erythematosus. J Rheumatol 1994;21:1976-7.

25. Trad S, Amoura Z, Beigelman C, et al. Pulmonary arterial hypertension is a major mortality factor in diffuse systemic sclerosis, independent of interstitial lung disease. Arthritis Rheum 2006;54:184-91.

26. Asherson RA, Cervera R. Review: Antiphospholipid antibodies and the lung. J Rheumatol 1995;22:62-6. 


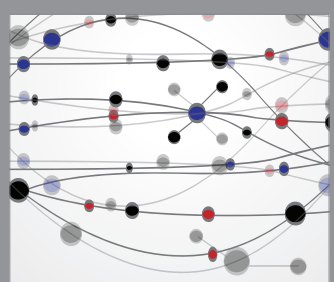

The Scientific World Journal
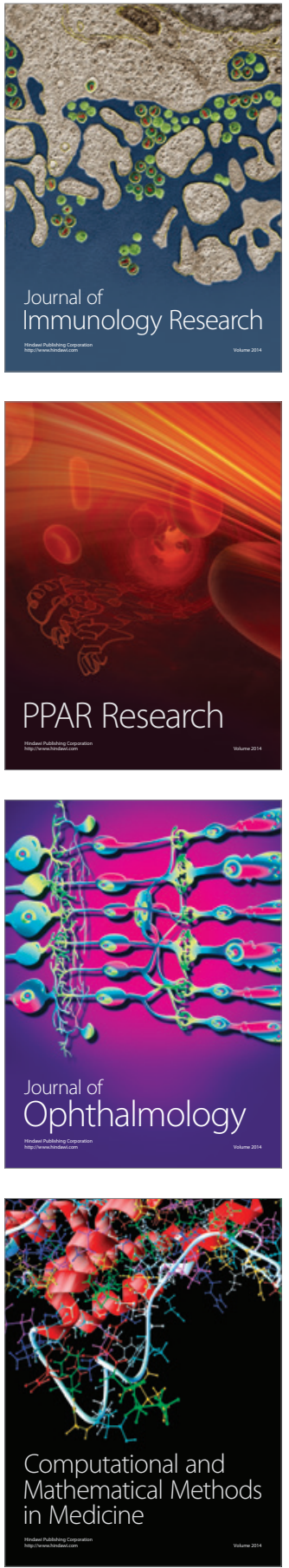

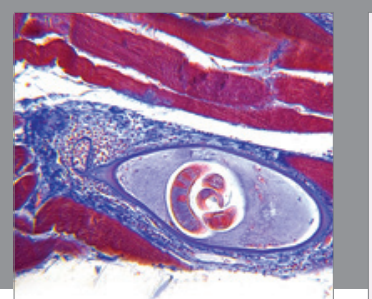

Gastroenterology Research and Practice

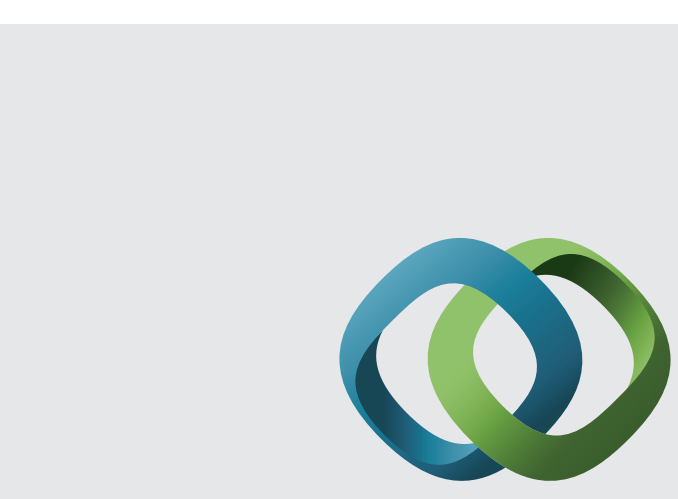

\section{Hindawi}

Submit your manuscripts at

http://www.hindawi.com
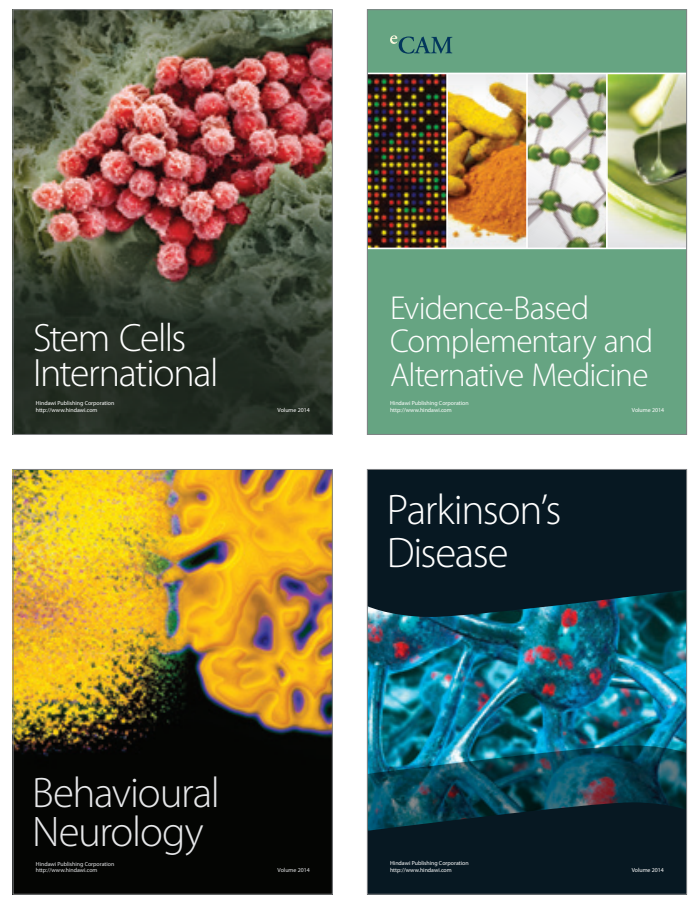
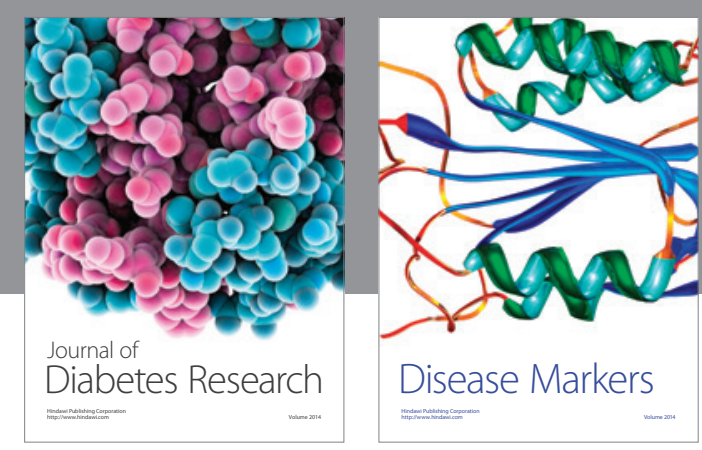

Disease Markers
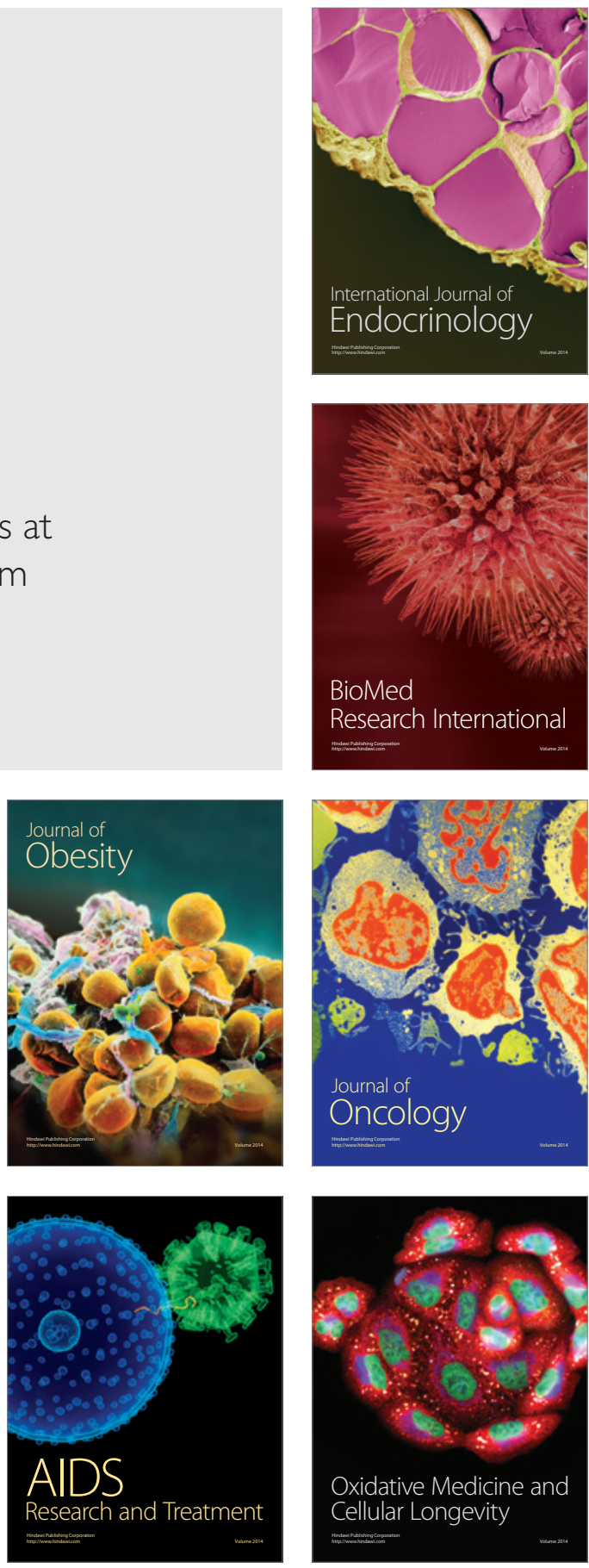